\title{
Elżbieta Bilska-Wodecka
}

\author{
Uniwersytet Jagielloński w Krakowie \\ Instytut Geografii i Gospodarki Przestrzennej \\ elzbieta.bilska-wodecka@uj.edu.pl \\ (D) https://orcid.org/0000-0003-0983-4768
}

\section{Postsekularyzm w badaniach geograficznych}

\begin{abstract}
Zarys treści: Celem artykułu jest prezentacja stanu badań geograficznych prowadzonych w nurcie postsekularyzmu. Geografia zaliczana jest do grupy tych dyscyplin naukowych, które jako jedne z pierwszych włączyły się w postsekularny dyskurs, nawiązując w warstwie teoretycznej do myśli Jürgena Habermasa. Geografowie w swoich badaniach podkreślają, że pomimo obserwowanego stopniowego powrotu religii do przestrzeni publicznej sekularyzacja i desekularyzacja mogą występować jednocześnie. Geografia wzbogaca myśl postsekularną o analizę interakcji sekularyzmu i sakralności w przestrzeni. Ważnym tematem badań jest wpływ symboliki lub kodu kulturowego na wyrażenie religijnej tożsamości osób i miejsc, ze szczególnym uwzględnieniem przestrzeni miejskiej. W badaniach geograficznych zwraca się też uwagę m.in. na kapitał duchowy człowieka (VBA) oraz działalność organizacji opartych na wierze (FBOs), których wolontariusze - o różnych tożsamościach religijnych - pracują na rzecz wykluczonych grup społecznych.
\end{abstract}

Słowa kluczowe: postsekularyzm, geografia religii, kapitał duchowy, geografia feministyczna, FBOs, miasto

\section{Wprowadzenie}

Myśl postsekularna jest jednym $z$ dyskursów prowadzonych obecnie w naukach społecznych i humanistycznych. Przedrostek „post-” może oznaczać koniec sekularyzmu, okres następujący po okresie sekularyzmu lub czas, w którym występuje nie tylko sekularyzm, ale widoczne jest też pojawianie się nowych wartości niemieszczących się w jego kategorii pojęciowej. Początek współczesnej debaty postsekularnej datuje się na przełom XX i XXI w. ${ }^{1}$ Termin postsekularyzm odnosi się

1 Na temat początków myśli postsekularnej zdania są podzielone. Jedna grupa badaczy sugeruje, że korzeni postsekularyzmu należy szukać w oświeceniu i romantyzmie, a obecna dyskusja jest kolejnym etapem jego rozwoju (Warchala 2013). Natomiast druga grupa dostrzega wcześniejsze pojedyncze studia mające cechy myśli postsekularnej, ale w swoich rozważaniach nie sięga do aż tak odległej historii i najczęściej odwołuje się do poglądów J. Habermasa (np. Beckford 2012). Pojawiają się też opinie (np. Puczydłowski 2016), że J. Habermas nie jest przedstawicielem postsekularyzmu. Dynamikę i naukowe znaczenie tego dyskursu podkreślają m.in. McLennan (2010), Burdziej (2010, s. 2) oraz Beaumont i Baker (red. 2011, s. 2), pisząc o postsekularnym zwrocie (postsecular turn). 
więc do szeregu poglądów dotyczących trwałości lub odradzania się tradycyjnych wierzeń i praktyk religijnych oraz rozwoju form duchowości niezwiązanych z systemami religijnymi. Cechą wspólną tych poglądów jest m.in. krytyczny stosunek do sekularyzacji. Postsekularyzm może być analizowany na różnych płaszczyznach. Obirek (2019) definiuje postsekularyzm nie tylko jako sposób myślenia, ale przede wszystkim jako działanie, którego celem jest zbudowanie trwałych, opartych na poszanowaniu wzajemnych odrębności, struktur społecznych i światopoglądów służących dobru wspólnemu. Zdaniem Beckforda (2012, s. 2) szeroki zakres znaczeń tego pojęcia daje możliwość badań zarówno $\mathrm{w}$ dyscyplinach nauk humanistycznych i społecznych, jak interdyscyplinarnych. Największe zainteresowanie zagadnieniami postsekularnymi jest obserwowane w teologii, religioznawstwie, filozofii, literaturoznawstwie, studiach postkolonialnych, socjologii, antropologii, politologii, stosunkach międzynarodowych i geografii.

Artykuł ma charakter przeglądowy. Jego celem jest ukazanie różnorodności dyskursów prowadzonych na temat postsekularyzmu oraz stanu i przykładów badań geograficznych w tym nurcie.

\section{Konteksty postsekularyzmu}

Doświadczenia przemian religijności oraz odchodzenia społeczeństwa od uczestnictwa $\mathrm{w}$ zorganizowanych formach praktyk religijnych - szczególnie widoczne od lat 60. XX w. - dały początek naukowym analizom sekularyzacji, rozpoczynając tym samym dyskurs o różnych aspektach tego zjawiska. Sekularyzacja jako proces społeczny doczekała się wielu interpretacji oraz grona zwolenników i przeciwników ${ }^{2}$. Sekularyzm - koncepcja wyjaśniająca brak integracji lub współzależności religii $z$ publicznymi sprawami społeczeństwa i państwa - $\mathrm{w}$ badaniach geograficznych zaczął być obecny dopiero w połowie lat 80 . XX w. (zob. Park 1994, s. 48-52, Rinschede 1999, s. 60-68). Naturalną konsekwencją utraty wiarygodności $\mathrm{w}$ dyskursie naukowym przez teorie sekularyzacyjne jest poszukiwanie nowych inspiracji służących wyjaśnianiu problemów i zróżnicowania współczesnego społeczeństwa. Częściową odpowiedź na te dylematy może dać postsekularyzm. Jest to nowy koncept, który stopniowo zyskuje na znaczeniu $\mathrm{w}$ naukach humanistycznych i społecznych, w tym również w geografii (np. Beckford 2012, Wigley 2018).

W swoich badaniach geografowie korzystali z różnych ujęć postsekularyzmu. Wielość interpretacji tej koncepcji zauważyli m.in. Beckford (2012) i Wigley (2018). W celu lepszej analizy genezy i znaczenia postsekularyzmu - uwzględniając kontekst naukowy i społeczny - Beckford (2012) podzielił obecne w nauce teoretyczne dyskursy na sześć grup.

Główną cechą poglądów zaliczonych do pierwszej grupy było przekonanie, że sekularyzm jako teoria nie do końca wyjaśniał przyczyny zaniku zorganizowanych form religii w niektórych częściach świata, a mógł być tylko parasolem

2 Kompendium wiedzy na temat sekularyzmu jest opracowanie Zielińskiej (2009). 
osłaniającym dynamiczne przemiany społeczne (np. Archer, Vaughan 1970, Sievernich 2003). Zdaniem Beckforda (2012, s. 3) „jednym z powodów wyboru myślenia w kategoriach postsekularnych jest przekonanie, że dominujące idee sekularyzacji i sekularyzmu były po prostu błędne i szkodliwe". Sekularyzm - ze względu na wieloznaczność samego pojęcia - nigdy nie był odpowiednią koncepcją, za której pomocą można by opisać zachodzące przemiany religijności. Poza tym w dyskursie naukowym zaczęły się pojawiać argumenty wskazujące, że problem sekularyzacji został wymyślony przez intelektualistów i elity (Hadden 1987, Morozov 2008). Pojęcie postsekularyzmu, definiowane w oparciu o poglądy prezentowane $\mathrm{w}$ pierwszej grupie, mogłoby więc zastąpić rzekomo nieprawidłowy sposób myślenia o sekularyzacji. Teoria sekularyzacji błędnie zakładała, że religia zaniknie (Jacobsen, Jacobsen 2008), a postsekularyzm jest nową teorią pozwalająca wyjaśnić zróżnicowane tempo sekularyzacji społeczeństwa lub odradzania się religii (Beckford 2012).

W drugiej grupie znalazły się dyskursy wskazujące na dualizm procesów, czyli równoczesne występowanie sekularyzacji i postsekularyzmu. Knott (2010) zwróciła uwagę, że we współczesnych miastach oba te zjawiska występują z różnym nasileniem. Równocześnie pojawia się nowa jakość myślenia, która wykracza poza ramy świeckie i bierze pod uwagę także obecność sfery religijnej (Harrington 2007). W sferze publicznej zaczyna być też obecny nowy sposób postrzegania rzeczywistości, polegający m.in. na odnajdywaniu wśród wielu cech typowych dla sekularyzacji również elementów religijnych (Goh 2011). W dyskusji o kondycji religijnej miasta podawano także argumenty teologiczne wskazujące na odchodzenie chrześcijaństwa od ortodoksyjnej tradycji, co z kolei jest postrzegane jako zaleta, ponieważ w przestrzeni pojawia się miejsce dla innych związków religijnych (Boeve 2008).

Trzecia grupa obejmuje studia podkreślające odradzanie się sacrum w kulturze. Szczególne miejsce zajmuje w niej literatura piękna, w której zaczynają być obecne wątki o tematyce religijnej (Bradley i in. 2010). Często też w powieściach pojawia się temat magii, okultyzmu i New Age (King 2005, Kyrlezhev 2008). Widoczny jest ponadto wzrost zainteresowania sztuką, w której występują elementy magii, cudów, czarów i inne znaki obecności bytu transcendentnego oraz przechodzenia z profanum do sacrum i vice versa (Beckford 2012).

W grupie czwartej mamy dyskursy wskazujące na obecność postsekularyzmu w polityce oraz powrót religii do przestrzeni publicznej, a w szczególności tej znajdującej się w miastach. Problematyka ta jest często przedmiotem badań geografii społecznej. Wśród nich znaczące miejsce zajmują opracowania dotyczące zagadnień FBOs ${ }^{3}$ (Beaumont, Dias 2008, Beaumont, Cloke red. 2012), czyli stowarzyszeń wyznaniowych działających podobnie jak pozarządowe organizacje pożytku publicznego. Beaumont (2010, s. 6) zauważył, że postsekularyzm to coś więcej niż odrodzenie religii $\mathrm{w}$ sferze publicznej. Oznaczać on może również wzajemne oddziaływanie „religijnych, humanistycznych i świeckich interesariuszy” w „zsekularyzowanych strukturach współczesnego społeczeństwa charakterystycznego

\footnotetext{
Skrót od angielskiego określenia faith-based organizations.
} 
dla późnego kapitalizmu”. Natomiast Bretherton (2011) zwrócił uwagę na lokalny wymiar postsekularyzmu. Jego zdaniem religie w postsekularnym społeczeństwie mogą mobilizować ludzi do działania na rzecz innych, zaprzeczając tym samym wszechobecnemu konsumpcjonizmowi. W rezultacie „elity nie mogą już lekceważyć publicznej obecności religii”, zwłaszcza w sferze społeczeństwa obywatelskiego, w której „pogoń za dobrami wspólnymi i ich ochrona” (Bretherton 2011, s. 358) będzie prawdopodobnie bardziej skuteczna niż zwykły dialog między lokalnymi grupami.

W grupie piątej znalazły się poglądy jednego z twórców koncepcji postsekularyzmu - niemieckiego filozofa i socjologa J. Habermasa (Habermas 2002, 2003, 2006, 2008a, b, 2010, 2011) - oraz tych autorów, którzy polemizowali z jego tezami (np. Altinordu 2008, Baumeister 2011) ${ }^{4}$.

Habermas (2010) zwrócił również uwagę na konieczność poszukiwania wzajemnego rozumienia „dobra wspólnego" między religiami i sekularyzmem oraz ponowne wspólne zaangażowanie się religii i polityki, zwłaszcza w spornych obszarach zarządzania i dostarczania usług publicznych. Jest on przekonany, że centralne instytucje państwa powinny pozostać świeckie, ale jednocześnie argumenty religijne społeczeństwa obywatelskiego mają prawo być wysłuchane w sferze publicznej (Habermas 2010). To uznanie potencjalnej wartości religii w życiu publicznym - szczególnie wartości moralnych opartych na wierze - jest dla Habermasa stosunkowo nowe i prawdopodobnie dlatego poczuł potrzebę użycia terminu „postsekularny” (Beckford 2012).

Grupa szósta obejmuje opracowania krytykujące myśl postsekularną. Zdaniem Dalfertha (2010) nie wskazuje ona tylko na odnowę zainteresowania religią czy duchowością, ale jest sposobem, w jaki scharakteryzowane są społeczeństwa lub państwa, które nie są ani religijne, ani świeckie. Dzieje się tak po części dlatego, że postsekularyzm jest często przedstawiany jako punkt końcowy rażąco uproszczonego historycznego przejścia od społeczeństw przedsekularnych przez sekularne do postsekularnych. Ta bardzo oryginalna interpretacja przedstawia stan postsekularny jako „obojętny na kwestie religii lub braku religii, a nie tylko pozostania w stanie neutralnym". Społeczeństwo postsekularne jest charakteryzowane jako „takie, w którym religia może być obecna i praktykowana lub nie, ale takie, w którym ten fakt nie ma szczególnego znaczenia" (Dalferth 2010, s. 335).

Do grupy sceptyków została również zaliczona geografka Kong (2010). Wskazała ona, że „teoria sekularyzacji wymaga wyjaśnienia i zbadania dowodów sekularyzacji, zanim zostanie zaakceptowana obecność postsekularyzacji oraz "ponowne pojawienie się" i ponowne zaangażowanie "tego, co święte i świeckie»" (Kong 2010, s. 764).

Beckford (2012) w swojej analizie dostrzegł także obecność postsekularnego feminizmu, jednak zaliczył go do drugiej grupy dyskursów. Ponowie analizując cytowane przez niego prace, uznałam, że dla tematów związanych z tym nurtem powinna być utworzona oddzielna grupa. Przemawiają za tym argumenty

4 Charakterystykę poglądów J. Habermasa można znaleźć zarówno w publikacjach w języku polskim (np. Warchala 2013, s. 75-77), jak i w języku angielskim (np. Matuštík 2006). 
teoretyczne odwołujące się m.in. do wizji Boga w badaniach teolożek feministycznych oraz stopniowej zmiany miejsca kobiet w społeczeństwie uważanym wciąż za patriarchalne. Trzeba zaakcentować, że znacząca większość studiów feministycznych została osadzona w kontekście miejskim (Bracke 2008, Braidotti 2008, Greed 2011). Greed (2011, s. 109) wskazała, że postsekularyzm może mieć wpływ na zauważenie „przestrzeni” i „możliwości” rozważenia znaczenia religii dla kobiet mieszkających w miastach, przy jednoczesnym zachowaniu obecnej „formy i kształtu miasta”. Obecność studiów feministycznych w myśli postsekularnej pozwoliło na dostrzeżenie niewidzialnej dotąd kobiecej przestrzeni miasta, ze szczególnym uwzględnieniem sfery religijnej.

\section{Postsekularyzm w geografii}

Złożoność i różnorodność zjawisk religijnych, ciągle wzrastające znaczenie indywidualnych doświadczeń religijnych oraz powstawanie nowych ruchów religijnych, były trudne do interpretacji z punktu widzenia teorii sekularyzacji. Większość badań geograficznych, szczególnie tych w nurcie geografii religii (Kong 1990, 2001), od początku lat 90. XX w. nie nawiązywała bezpośrednio do myśli postsekularnej, lecz poprzez liczne konteksty społeczne i przestrzenne wskazywała na obecność oraz wzajemne relacje pomiędzy sacrum i profanum w przestrzeni (Glasze, Schmitt 2018). Dlatego zdaniem Kong (2010) wśród nowych problemów badawczych powinny znaleźć się również te związane z postsekularyzmem. W pierwszej dekadzie XXI w. w ślad za innymi naukami społecznymi w dyskursie naukowym geografii religii zaczynają pojawiać się pierwsze badania prowadzone w nurcie postsekularyzmu (zob. np. Beaumont 2004, Cloke i in. 2005). Wspomina o tym Kong (2010), charakteryzując dorobek geografii religii w pierwszej dekadzie XXI w., oraz Wigley (2018).

Głos podsumowujący dotychczasowe rozważania na temat sekularyzacji i postsekularyzmu w geografii zabrali Glasze i Schmitt (2018). Ich zdaniem adaptacja postsekularyzmu w geografii społecznej i geografii kultury dała już pierwsze impulsy do badań. Pewną jego wadą jest eurocentryzm. Konieczna jest zatem głębsza dyskusja na temat charakteru świeckości i połączenia perspektywy postsekularnej z podejściami z geografii społecznej i geografii kultury. Obejmuje to badanie roli praktyk uważanych za religijne lub świeckie w symbolicznej i materialnej przestrzeni (publicznej) lub analizę konkretnych „ścieżek regionalnych” w przypadku prób delimitacji występowania świeckości i religii w przestrzeni (Glasze, Schmitt 2018).

Cloke i in. (2019) w publikacji „Geographies of Postsecularity”, omawiając potencjalne tematy badawcze, $z$ optymizmem twierdza, że postsekularyzm może znacząco przyczynić się do dostrzeżenia możliwości dzielenia życia we wspólnocie oraz dbania o wspólne dobra, takie jak sprawiedliwość społeczna, dobrobyt, równość, solidarność czy szacunek dla odmienności. Chociaż sfera religijna i świecka są często definiowane jako przeciwieństwa, geografia może dać zarówno możliwość analizy każdej z tych sfer oddzielnie, jak i w ich wzajemnej interakcji. 
Interdyscyplinarny charakter myśli postsekularnej może stwarzać problem z przypisaniem jej do konkretnej subdyscypliny geografii. Ze względu na kontekst teoretyczny badania takie umieszczane są w nurcie geografii religii, natomiast ze względu na tematykę np. w geografii społecznej czy geografii kultury.

\section{Wybrane przykłady badań geograficznych}

Badania geograficzne prowadzone w nurcie postsekularyzmu można klasyfikować, stosując różne kryteria. Najbardziej naturalny wydaje się jednak podział na trzy grupy. Do pierwszej będą należały badania skoncentrowane na człowieku jako niezależnej jednostce, jego wartościach, poglądach, postrzeganiu i zachowaniu się w przestrzeni oraz skutkach działania. Drugą grupę stanowią badania poświęcone działaniom i relacjom $\mathrm{w}$ różnych grupach społecznych, ze szczególnym uwzględnieniem wartości zarówno religijnych, jak i uniwersalnych/świeckich, jakie wnoszą do tej grupy jej członkowie, oraz celów działania takiej grupy. Do trzeciej grupy zostaną zaliczone analizy przestrzeni pod kątem skutków działania człowieka i różnych grup.

\section{Człowiek}

Badania w nurcie postsekularyzmu skoncentrowane na osobie obejmują analizę wpływu religii/duchowości na zachowania w domu, w drodze do pracy, w miejscu pracy, w przestrzeni (sąsiedzkiej, miejskiej). Niektóre z nich analizują ilość czasu, jaki jest przeznaczany w ciągu dnia na czynności religijne, w tym przede wszystkim na modlitwę, i tym samym wpisują się do grupy badań poświęconych budżetom czasu.

Postsekularyzm zainspirował do prowadzenia badań nad wpływem cech indywidualnych człowieka na jego funkcjonowanie w społeczeństwie. Wartości te są określane jako kapitał duchowy (VBA). Składa się on z wartości (values), wiary (belief) i postaw (attitudes). Autorzy sugerują, że kapitał duchowy (VBA) jest często ukrywany przed opinią publiczną z powodów zarówno osobistej powściągliwości, jak i skromności, ale także z obawy przed publicznym wyrażaniem wiary religijnej lub postawy duchowej w miejscu pracy (Stokes i in. 2016) albo w miejscu publicznym. Postawa ta może wynikać z lęku przed napiętnowaniem czy brakiem akceptacji ze względu na odmienne poglądy.

Kapitał duchowy (VBA) może jednak mieć znaczący wpływ m.in. na funkcjonowanie demokratycznego państwa czy ujednolicenie i humanizowanie otoczenia korporacyjnego poprzez motywowanie działań w odniesieniu do tkanki publicznej w określonym kontekście pracy (Stokes i in. 2016). Uwzględnianie go w badaniach może pokazać dynamiczną zależność między różnymi formami kapitału społecznego w środowisku korporacyjnym i w przestrzeni publicznej oraz wyjaśnić ich konsekwencje dla zarządzania firmą (Stokes i in. 2016).

Drugim tematem badawczym podejmowanym w kontekście postsekularnym jest analiza miejsc, w których osoba odprawia codzienne praktyki religijne, oraz 
czasu, jaki na nie poświęca (np. Wigley 2018). Podobne tematy realizowane są też w nurcie geografii feministycznej i opisują zachowania kobiet. Klingorová (2020) zauważa, że skupienie się na osobistych, codziennych doświadczeniach kobiet może dać nowe spojrzenie na zrozumienie związku między religią a przestrzenią. Szczególnie ważny jest w tym przypadku dobór grupy badawczej. Powinny się w niej znaleźć te kobiety, które podejmują różne działania w stowarzyszeniach religijnych, parafiach czy innych organizacjach o charakterze religijnym. Podejścia feministyczne odzwierciedlają również ogólne trendy społeczne w społeczeństwie czeskim, które są związane z postmodernizmem i określane jako postsekularne W sferze przemian religijnych.

W społeczeństwie postsekularnym religia nie polega już tylko na odwiedzaniu kościoła w niedzielę, ale także na doświadczaniu codziennych chwil poprzez etykę religijną i nieformalne praktyki duchowe. Religia jako osobiste, emocjonalne codzienne doświadczenie przestrzeni jest kluczowym czynnikiem w tworzeniu indywidualnej tożsamości osoby. Nie tylko ludzie wyznający jakąś tradycyjną religię, ale też ci, którzy nie deklarują instytucjonalnej religijności, doświadczają własnej duchowości (Klingorová, Gökarıksel 2018, Klingorová 2020).

\section{Społeczeństwo}

Społeczeństwo postsekularne jest często opisywane jako to, w którym jest miejsce do aktywnego działania zarówno dla osób wierzących, jak i niewierzących. Ważną rolę w przestrzeni społecznej pełnią organizacje i grupy wyznaniowe świadczące usługi społeczne lub publiczne. Cechą charakterystyczną tych stowarzyszeń jest unikanie manifestowania tożsamości religijnej poprzez symbolikę lub kody kulturowe (Dalferth 2010, Cloke, Beaumont 2013).

Szczególne pole badawcze jest poświęcone osobom wykluczonym oraz organizacjom zaangażowanym w pomoc dla nich (Beaumont, Dias 2008, Bradley 2009, Cloke 2010, Beaumont, Cloke red. 2012, Williams 2012, 2015, Williams i in. 2012, May, Cloke 2014), np. geografia bezdomności (geographies of homelessness). W tym kontekście ważne miejsce zajmują organizacje oparte na wierze (ang. Faith Based Organisations - dalej: FBOs). To pojęcie określa różnego rodzaju fundacje i stowarzyszenia, w których na „różne sposoby i w różnym stopniu wiara kształtuje lub ma wpływ na ich [wolontariuszy - przyp. EB-W] pracę” (Bradley 2009, s. 101). Pojawienie się i aktywność FBOs w przestrzeni publicznej, jak zauważył Cloke (2010), były spowodowane prowadzeniem przez rządy neoliberalnej polityki gospodarczej i stopniowym wycofywaniem się państwa ze świadczenia niektórych rodzajów usług społecznych. W ten sposób powstała luka, która zaczęła być wypełniania przez działalność zarówno grup wyznaniowych, jak i w coraz większym stopniu przez profesjonalne organizacje usługowe (Beaumont, Dias 2008).

May i Cloke (2014) wydzielili trzy rodzaje organizacji opartych na wierze (FBOs). Pierwszy z nich obejmuje organizacje, w których członkostwo jest inspirowane religijnie, a wolontariusze wywodzą się z jednej tradycji religijnej. Do drugiego rodzaju zalicza się organizacje, których członkowie wywodzą się z różnych tradycji religijnych. Trzecią grupę stanowią misjonarze. 
Motywacje wolontariuszy do podejmowania aktywności w FBOs, przestrzenie ich działań oraz skutki pracy i zasięg oddziaływania w miastach były i nadal są przedmiotem wielu analiz. Temat FBOs jest jednym z częściej podejmowanych w kontekście postsekularyzmu. Kompendium wiedzy o tym zagadnieniu jest opracowanie pod redakcją Beaumonta i Cloke’a (2012).

\section{Przestrzeń}

Z powodu dużej różnorodności - zarówno pod względem urbanistycznym, funkcjonalnym, jak i społecznym - szczególnie te największe miasta są częstym przedmiotem badań w nurcie postsekularnym (Molendjik i in. red. 2010, Beaumont, Baker red. 2011). Często podejmowanym tematem badawczym są przemiany krajobrazu religijnego i jego symboliki oraz przestrzenne skutki działalności człowieka religijnego (homo religiosus).

Na podstawie form działalności zostały opracowane dwie typologie przestrzeni społecznego zaangażowania w miastach. Pierwsza $\mathrm{z}$ nich jest autorstwa Beaumonta i Cloke'a (2012). Wydzielili oni: (1) przestrzenie wspólnoty i uczestnictwa, w których dochodzi m.in. do rozwijania, zrozumienia i tworzenia relacji między odmiennymi grupami (religijnymi lub etnicznymi); (2) przestrzenie opieki (szczególnie nad osobami bezdomnymi); (3) przestrzenie czynnej wiary, niekoniecznie tożsame z obiektami sakralnymi; (4) przestrzenie interakcji z gospodarką.

Drugą klasyfikację opracowali Cloke i in. (2019) (tab. 1). Nawiązuje ona do wcześniejszych poglądów jednego z autorów. Twierdził on, że przestrzeń publiczna jest kształtowana przez ciągłe interakcje sekularyzacji i sekularyzmu (jako

Tabela 1. Cechy charakterystyczne przestrzeni w mieście i związane z nimi formy działalności

\begin{tabular}{|c|c|}
\hline $\begin{array}{l}\text { Cechy charakterystyczne } \\
\text { przestrzeni }\end{array}$ & Formy działalności \\
\hline $\begin{array}{l}\text { opieka nad potrzebują- } \\
\text { cymi }\end{array}$ & $\begin{array}{l}\text { opieka nad bezdomnymi, azylantami i innymi potrzebującymi opieki } \\
\text { sprawowana najczęściej przez FBOs }\end{array}$ \\
\hline $\begin{array}{l}\text { opór wobec neoliberalnej } \\
\text { polityki i działania na } \\
\text { rzecz jej przemiany }\end{array}$ & $\begin{array}{l}\text { działanie poza podziałami religijnymi na rzecz wykluczonych, często } \\
\text { wbrew obowiązującemu prawu }\end{array}$ \\
\hline identyfikacja etniczna & $\begin{array}{l}\text { łączenie interesów grup etnicznych wyrażających wartości religijne lub } \\
\text { świeckie oraz tworzenie miejsc, gdzie takie spotkania mogą się odbywać }\end{array}$ \\
\hline protesty społeczne & $\begin{array}{l}\text { pluralistyczna wrażliwość i organizacja ruchów społecznych stara się } \\
\text { akcentować swoją obecność poprzez znaki, symbole, protesty i przed- } \\
\text { stawienia religijne lub świeckie w przestrzeni publicznej }\end{array}$ \\
\hline $\begin{array}{l}\text { lokalne pojednanie i tole- } \\
\text { rancja }\end{array}$ & $\begin{array}{l}\text { liderzy lokalni i grupy wolontariuszy pracują na rzecz likwidacji napięć } \\
\text { społecznych oraz podziałów międzyreligijnych, antyreligijnych lub } \\
\text { antyświeckich w skali lokalnej }\end{array}$ \\
\hline $\begin{array}{l}\text { wolontariat lub wsparcie } \\
\text { charytatywne i solidar- } \\
\text { ność społeczna }\end{array}$ & $\begin{array}{l}\text { obejmuje projekty etyczne mające na celu m.in. opiekę nad wykluczo- } \\
\text { nymi społecznie i ubogimi, a ich przeprowadzenie zależy od wsparcia } \\
\text { finansowego i dobrowolnej pracy osób z innych części miasta niż } \\
\text { pochodzą potrzebujący, zwykle z zamożniejszych przedmieść }\end{array}$ \\
\hline
\end{tabular}

Źródło: opracowanie własne na podstawie Cloke i in. (2019, s. 89-93). 
ideologii politycznej i kulturowej), ale musi być też przestrzenią negocjacji (postsekularną - przyp. EB-W), w której trzeba zrobić miejsce na ponowne pojawienie się religii i duchowości (Beaumont, Baker red. 2011).

Postsekularne miasto może cechować się dużym zróżnicowaniem pod względem etnicznym i religijnym (Gorski, Altınordu 2008). Może także być areną konfliktów spowodowanych aktywnością fundamentalistycznych grup religijnych (Wilson, Steger 2013), co z kolei daje duże możliwości badań przestrzennych i społecznych interakcji pomiędzy tymi grupami (np. Gökarıksel, Secor 2015).

W postsekularnym mieście obecne są symbole lub kod kulturowy, które mogą być czynnikiem kreującym religijną tożsamość miejsc i ludności (Knott 2010, Stevenson i in. 2010, Havlicek, Klingorova 2017). Dostrzega się także przenikanie religii do kultury popularnej i „świeckich” dyskursów (Molendjik i in. 2010, Beaumont, Baker 2011) oraz występowanie interakcji pomiędzy sferą religijną a świecką w przestrzeni publicznej (Cloke, Beaumont 2013).

Niektóre miasta mogą charakteryzować się dużą dynamiką procesów sekularyzacji i desekularyzacji w przestrzeni (Sturm 2013, Havlíček, Klingorová 2018). Wnioski takie można wysnuć na podstawie analizy aktywności wiernych lub istnienia obiektów sakralnych różnych wyznań (Stevenson i in. 2010, Olson i in. 2013, Henkel 2014, Havlíček, Klingorová 2017, della Dora 2018).

Miasto jest postrzegane jako miejsce, w którym łatwo zauważalna jest zarówno skala przestrzenna rozmaitych problemów związanych z wykluczeniem społecznym, jak i działalność wolontariuszy opierająca się na różnych motywacjach: religijnej, religijnej i świeckiej lub świeckiej. Tutaj również jest widoczna i intensywnie skoncentrowana przestrzeń ubóstwa oraz patologii społecznej, co znajduje odzwierciedlenie w społeczno-przestrzennej wrażliwości osób religijnych i świeckich dostrzegających nierówności społeczne (Cloke, Beaumont 2013).

Praga jest interesującym przykładem badań obecności religii w przestrzeni publicznej. Elementy zwiększonej widoczności religii, pluralizm religijny oraz wzajemne oddziaływania pomiędzy religiami, procesy sekularyzacji i desekularyzacji, którym towarzyszy sakralizacja miejsc publicznych w przestrzeni miejskiej, są widoczne w krajobrazie religijnym we wszystkich dzielnicach tego miasta, ale różnią się kontekstem przestrzennym, historycznym i społecznym. Praga oferuje przestrzeń do funkcjonowania dla wielu kultur religijnych, ale rola religii jako całości jest nadal marginalizowana. Sprzeczne procesy związane z postsekularyzmem, takie jak sekularyzacja społeczeństwa i sakralizacja krajobrazu, działają równolegle $\mathrm{w}$ kontekście miasta $\mathrm{z}$ dziedzictwem postkomunistycznym. Zauważa się rosnące znaczenie nowych ruchów religijnych, nowych ruchów chrześcijańskich (głównie ewangelickich) i alternatywnych duchowości (Havlíček, Klingorová 2017).

\section{Podsumowanie}

Myśl postsekularna jest konceptem stosunkowo młodym i bardzo szybko znalazła swoje miejsce w badaniach geograficznych. Pomimo wielu głosów krytycznych 
geografom daje ona możliwość interpretacji współczesnej rzeczywistości XXI w. - w bardzo wielu aspektach. Niewątpliwie koncepcja ta znajduje zastosowanie w wyjaśnianiu współczesnych przemian religijności w skali krajów i miast, a rzadziej regionów, umożliwia prowadzenie analiz różnych rodzajów aktywności wynikających z motywów religijnych w mniejszej skali przestrzennej (Bilska-Wodecka i in. 2019), np. obszarów podmiejskich czy wiejskich. Mogła ona mieć wpływ na rozpoczęcie badań nad problematyką bezdomności i różnych form wykluczenia społecznego. Niewykorzystane jest natomiast pole badawcze obejmujące problematykę religijności, udziału w organizacjach religijnych oraz dziennej aktywności religijnej wynikającej ze zróżnicowania etnicznego i płciowego.

\section{Literatura}

Archer M.S., Vaughan M. 1970. Education, secularization, desecularization and resecularization. A Sociological Yearbook of Religion in Britain, 3(1): 130-145.

Baumeister A. 2011. The Use of "Public Reason" by Religious and Secular Citizens: Limitations of Habermas' Conception of the Role of Religion in the Public Realm. Constellations, 18: 222-243.

Beaumont J.R. 2004. Workfare, associationism and the "underclass" in the United States: contrasting faith-based action on urban poverty in a liberal welfare regime. [W:] H. Noordegraaf, R. Volz (red.), European churches confronting poverty: Social action against social exclusion. SWI Verlag, Bochum, s. 249-278.

Beaumont J. 2010. Transcending the particular in postsecular cities. [W:] A. Molendijk, J. Beaumont, C. Jedan (red.), Exploring the postsecular: The religious, the political, and the urban. Brill, Leiden-Boston, s. 3-17.

Beaumont J., Baker C. (red.) 2011. Postsecular Cities: space, theory and practice. Contiuum, London.

Beaumont J., Cloke P. (red.) 2012. Faith-Based Organisations and Exclusion in European Cities. The Policy Press, Bristol.

Beaumont J., Dias C. 2008. Faith-based organisations and urban social justice in the Netherlands. Tijdschrift voor Economische en Sociale Geografie, 99(4): 382-392.

Beckford J. 2012. SSSR Presidential Address Public Religions and the Postsecular: Critical Reflections. Journal for the Scientific Study of Religion, 51(1): 1-19.

Bilska-Wodecka E., Jackowski A., Sołjan I. 2019. Geography of religion at the turn of the 21 st century - historical and contemporary issues. Historia Religionum, 11: 15-28.

Boeve L. 2008. Religion after detraditionalization: Christian faith in a postsecular Europe. [W:] G. Ward, M. Hoelzl (red.), The new visibility of religion: Studies in religion and cultural hermeneutics. Continuum, London, s. 187-209.

Burdziej S. 2010. Socjologia postsekularna? Studia Socjologiczne, 2(197): 89-107.

Bracke S. 2008. Conjugating the modern/religious, conceptualizing female religious agency: Contours of a "postsecular" conjuncture. Theory, Culture and Society, 25(6): 51-67.

Bradley A., Carruthers J., Tate A. 2010. Introduction: Writing post-secularity. [W:] J. Carruthers, A. Tate (red.), Spiritual identities: Literature and the post-secular imagination. Peter Lang, Bern, s. $1-8$.

Bradley T. 2009. A call for clarification and critical analysis of the work of faith-based development organizations (FBDO). Progress in Development Studies, 9(2): 101-114.

Braidotti R. 2008. In spite of the times: The postsecular turn in feminism. Theory, Culture, and Society, 25(6): 1-24.

Bretherton L. 2011. A postsecular politics? Inter-faith relations as a civic practice. Journal of the American Academy of Religion, 79(2): 346-377.

Cloke P. 2010. Theo-ethics and radical faith-based praxis in the postsecular city. [W:] A. Molendijk, J. Beaumont, C. Jedan (red.), Exploring the postsecular: The religious, the political, and the urban. Brill, Leiden-Boston, s. 223-241. 
Cloke P., Baker Ch., Sutherland C., Williams A. 2019. Geographies of Postsecularity. Re-envisioning Politics, Subjectivity and Ethics. Routledge, London-New York.

Cloke P., Beaumont J. 2013. Geographies of postsecular rapprochement in the city. Progress in Human Geography, 37(1): 27-51.

Cloke P., Johnsen S., May J. 2005. Exploring ethos? Discourses of 'charity' in the provision of emergency services for homeless people. Environment and Planning A, 37(3): 385-402.

Dalferth I.U. 2010. Post-secular society: Christianity and the dialectics of the secular. Journal of the American Academy of Religion, 78(2): 317-345.

Dora V. della 2018. Infrasecular geographies: Making, unmaking and remaking sacred space. Progress in Human Geography, 42(1): 44-71.

Glasze G., Schmitt T.G. 2018. Understanding the geographies of religion and secularity: on the potentials of a broader exchange between geography and the (post-) secularity debate. Geographica Helvetica, 73(4): 285-300.

Goh R.B.H. 2011. Market theory, market theology: The business of the church in the city. [W:] J. Beaumont, C. Baker (red.), Postsecular cities: Space, theory and practice. Continuum, London, s. 50-68.

Gorski P.S., Altinordu A. 2008. After secularization? Annual Review of Sociology, 34(1): 55-85.

Gökarıksel B., Secor A.J. 2020. Affective geopolitics: Anxiety, pain, and ethics in the encounter with Syrian refugees in Turkey. Environment and Planning C: Politics and Space, 38(7-8): 1237-1255.

Greed C. 2011. A feminist critique of the postsecular city: God and gender. [W:] J. Beaumont, C. Baker (red.), Postsecular cities: Space, theory and practice. Continuum, London, s. 104-119.

Habermas J. 2002. Religion and rationality: Essays on Reason, God and Modernity (Studies in Contemporary German Social Thought). Polity Press, Cambridge.

Habermas J. 2003. The future of human nature. Polity Press, Cambridge.

Habermas J. 2006. Religion in the public sphere. European Journal of Philosophy, 14(1): 1-25.

Habermas J. 2008a. Notes on a post-secular society (http://www.signandsight.com/features/1714. html; dostęp: 1211.2020).

Habermas J. 2008b. Between naturalism and religion. Philosophical essays. Polity Press, Cambridge.

Habermas J. 2010. A reply. [W:] N. Brieskorn, J. Habermas, M. Reder, F. Ricken, J. Schmidt (red.), An awareness of what is missing: Faith and reason in a post-secular age. Polity Press, Cambridge, s. $72-83$.

Habermas J. 2011. "The political": The rational meaning of a questionable inheritance of political theology. [W:] E. Mendieta, J. Vanantwerpen (red.), The power of religion in the public sphere. Columbia University Press, New York, s. 15-33.

Hadden J.K. 1987. Toward desacralizing secularization theory. Social Forces, 65(3): 587-611.

Harrington A. 2007. Habermas and the "post-secular" society. European Journal of Social Theory, 10(4): 543-560.

Havlicek T., Klingorova K. 2017. City with or without God? Features of post-secularism in religious landscape of post-communist Prague. Social \& Cultural Geography, 19(6): 789-811.

Henkel R. 2014. The changing religious space in (large) Western European cities. Prace Geograficzne, 137: 7-15.

Herman A., Beaumont J., Cloke P., Walliser A. 2012. Spaces of Postsecular Engagement in Cities. [W:] J. Beaumont, P. Cloke (red.), Faith-Based Organisations and Exclusion in European Cities. The Policy Press, Bristol, s. 59-80.

Jacobsen D., Jacobsen R.H. 2008. Postsecular America: A new context for higher education. [W:] D. Jacobsen, R.H. Jacobsen (red.), The American university in a postsecular age. Oxford University Press, New York, s. 3-15.

King M. 2005. Art and the postsecular. Journal of Visual Art Practice, 4(1): 3-17.

Klingorová K. 2020. Feminist approaches in the geographies of religion: experience, emotions, everydayness and embodiment in postsecular society and space. AUC Geographica, 55(1): 123-133.

Klingorová K., Gökarıksel B. 2018. 'God was with me everywhere': women’s embodied practices and everyday experiences of sacred space in Czechia. Gender, Place \& Culture, 25(1): 37-60.

Knott K. 2010. Cutting through the postsecular city: A spatial interrogation. [W:] A.L. Molendijk, J. Beaumont, C. Jedan (red.), Exploring the postsecular: The religious, the political and the urban. Brill, Leiden, s. 19-38. 
Kong L. 1999. Geography and religion: trends and prospects. Progress in Human Geography, 14(3): 355-371.

Kong L. 2001. Mapping 'new' geographies of religion: politics and poetics in modernity. Progress in Human Geography, 25(2): 211-233.

Kong L. 2010. Global shift, theoretical shift: Changing geographies of religion. Progress in Human Geography, 34(6): 755-776.

Kyrlezhev A. 2008. The postsecular age: Religion and culture today. Religion, State and Society, 36(1): 21-31.

Martin D. 1969. The Religious and the secular: Studies in secularization. Routledge and Kegan Paul, Oxford.

Martin D. 2011. The Future of Christianity. Reflections on Violence and Democracy, Religion and Secularization. Ashgate, Farnham.

Matuštík M.B. 2006. Habermas' turn? Philosophy \& Social Criticism, 32(1): 21-36.

May J., Cloke P. 2014. Modes of attentiveness: reading for difference in geographies of homelessness. Antipode, 46(4): 894-920.

McLennan G. 2010. The Postsecular Turn. Theory, Culture \& Society, 27(4): 3-20.

Molendjik A.L., Beaumont J., Jedan C. (red.) 2010. Exploring the Postsecular: the religious, the political and the urban. Brill, Leiden-Boston.

Morozov A. 2008. Has the postsecular age begun? Religion, State and Society, 36(1): 39-44.

Obirek S. 2019. Postsekularyzm jako alternatywa dla sekularyzacji (http://www.humanizm.net.pl/ postsekularyzm.html; dostęp: 12.11.2020).

Olson E., Hopkins P., Pain R., Vincett G. 2013. Retheorizing the Postsecular Present: Embodiment, Spatial Transcendence, and Challenges to Authenticity Among Young Christians in Glasgow, Scotland. Annals of the Association of American Geographers, 103(6): 1421-1436.

Park Ch.C. 1994. Sacred Worlds: Introduction to Geography and Religion. Routledge, London.

Puczydłowski M. 2016. Filozofia Jürgena Habermasa wobec zwrotu postsekularnego. Kwartalnik Filozoficzny, 44(1): 155-169.

Rinschede G. 1999. Religionsgeographie. Westermann, Braunschweig.

Sievernich M. 2003. Pastoral care for the sick in a post-secular age: An Ignatian perspective. Christian Bioethics, 9(1): 23-37.

Stevenson D., Dunn K., Possamai A., Piracha A. 2010. Religious belief across "postsecular" Sydney: the multiple trends in (de)secularisation. Australian Geographer, 41(3): 323-50.

Stokes P., Baker C., Lichy J. 2016. The Role of Embedded Individual Values, Belief and Attitudes and Spiritual Capital in Shaping Everyday Postsecular Organizational Culture. European Management Review, 13(1): 37-51.

Warchala M. 2013. Postsekularne konstelacje nowoczesności. O historycznych związkach religii i nauk społecznych. Stan Rzeczy, 2(5): 75-92.

Wigley E. 2018. Unofficial geographies of religion and spirituality as postsecular spaces. [W:] J. Beaumont (red.), The Routledge Handbook of Postsecularity. Routledge, London-New York, s. 371-382.

Williams A. 2012. Moralising the poor? Faith-based organizations, Big Society and contemporary workfare policy. [W:] J. Beaumont, P. Cloke (red.), Faith-Based Organizations and Exclusion in European Cities. Policy Press, Bristol, s. 173-198.

Williams A. 2015. Postsecular Geographies: Theo-ethics, Rapprochement and Neoliberal Governance in a Faith-based Drug Programme. Transactions, Institute of British Geographers, 40(2): 192-208.

Williams A., Cloke P., Thomas S. 2012. Contesting co-option: Faith-based organizations, social exclusion and neoliberal urban governance. Environment and Planning A, 44(6): 1479-1501.

Wilson E.K., Steger M.B. 2013. Religious globalism in the post-secular age. Globalizations, 10(3): 481-495.

Zielińska K. 2009. Spory wokół teorii sekularyzacji. Nomos, Kraków. 


\title{
Post-secularism in geography research
}

\begin{abstract}
The aim of the paper is to discuss the state of geography research in the area of post-secularism. Geography was one of the first research disciplines to investigate issues in terms of the new concept of post-secularism, which is a relatively new concept. The most frequently cited geography works in this area are those of the German philosopher and sociologist Jürgen Habermas who is widely considered to be one of the formulators of this concept.

Post-secularism is defined as not only a manner of thinking but also primarily a way of acting - the purpose of which is to build strong social structures based on respect for differences, regardless of religious, political and ethnic background. This form of mutual respect is supposed to serve the welfare of what is broadly defined as the community.

One of the main ideas in post-secularism is the recognition that public spaces are characterized by the interaction of the religious sphere and secular sphere. The discipline of geography contributes to post-secularism, which questions the ongoing secularization of society, via an analysis of the interaction between secularism and the sacred in geographic space.

Hence, the relationship between secularism and post-secularism may be considered interesting. While religion is returning to public spaces in many cases, secularization may continue to occur at the same time. In many countries the processes of secularization and de-secularization tend to occur at the same time.

Geographers examining post-secularism often note the work of various types of organizations that serve the so-called public good, where religious undertones infiltrate the popular culture as well as secular discourse. In many cases, researchers argue, the work of these types of organizations may be less visible in public spaces, especially in the case of entities serving unempowered social groups, due to the low visibility of the religious affiliation of their volunteers.

One other important part of research on post-secularism is symbolism or the cultural code that maintains and also affects the religious identity of people and places. In this context, it is vital to examine the spiritual capital of individuals (i.e. VBA - values, beliefs, and attitudes). While VBA often remains hidden from public view for many different reasons, it may produce a powerful and meaningful impact on community relationships; for example, collegial relationships in the workplace.
\end{abstract}

Key words: post-secularism, geography of religion, spiritual capital, feminist geography, FBOs, city 